\title{
Application of Critical Classroom Discourse Analysis (CCDA) in Analyzing Classroom Interaction
}

\author{
Sima Sadeghi \\ $\mathrm{PhD}$ candidate, on sabbatical leave in the Netherlands \\ English Department, Faculty of Foreign Languages, University of Isfahan, Isfahan, Iran \\ E-mail: sima_sadeghi23i@yahoo.com \\ Saeed Ketabi \\ Associate Professor, University of Isfahan, Iran \\ E-mail: ketabi@fgn.ui.ac.ir \\ Mansoor Tavakoli \\ Associate Professor, University of Isfahan, Iran \\ E-mail: mrtavakoli14@gmail.com \\ Moslem Sadeghi \\ M.A in Translation, Azad University of Bandar Abbas, Iran \\ E-mail: moslemsadeghi29@yahoo.com
}

Received: August 11, 2011

Accepted: December 21, 2011

Published: January 1, 2012

doi:10.5539/elt.v5n1p166

URL: http://dx.doi.org/10.5539/elt.v5n1p166

\begin{abstract}
As an area of classroom research, Interaction Analysis developed from the need and desire to investigate the process of classroom teaching and learning in terms of action-reaction between individuals and their socio-cultural context (Biddle, 1967). However, sole reliance on quantitative techniques could be problematic, since they conceal more than they reveal of the intricacies of classroom interaction. Moving away from this quantitative norm, this study examines the classroom process from the discourse analysis perspective called Critical Classroom Discourse Analysis (CCDA), proposed by Kumaravadivelu (1999); which draws on Poststructuralism and postcolonialism concepts of discourse; to analyze and understand classroom input and interaction in terms of power and dominance.

This ethnographic study aimed at using CCDA as a tool for critical reflection to analyze the differences in the discourse of males and females in an EFL situation. The discussion, based on a case study conducted at a university classroom in Iran, aims at understanding the unseen social processes, i.e. male dominance in discourse. Transcriptions of classroom interactions were put into a qualitatively interpretation of males and females' adherence to, or flouting of four maxims. The research findings suggest that male dominance could be concealed in discourse control, types of questions, and turn-taking. Male participants tended to exert more power and used less indirect language, more negative face, and fewer politeness phenomena.
\end{abstract}

Keywords: Critical Classroom Discourse Analysis, EFL context, Power/Dominance

\section{Introduction}

"We are the interaction boys,

We analyze amid the noise

of classroom struggles, though we die

With failing hands we hold pens high..."

(Nicolas, 1968)

There has been a growing interest among the educators and researchers to analyze the classroom process, especially 
the interaction among participants. The term "interaction" implies an action-reaction or a two-way influence which may be between individuals (e.g. pupil-pupil, or teacher-target) or between an individual and a group (e.g. teacher-audience) or between materials and individuals. (Biddle, 1967)

Mainstream SLA research is mostly criticized for not being able to capture the complexity of the language learner, Learner's multiple identities (Peirce, 1995; Norton 2000), and the processes of language learning. For instance, McClellan (1971) in a critique of classroom research states that investigators are more concerned with studying manners in the classroom than the essential features of what is said, done and made. Thus, various models of classroom interaction/discourse analysis; such as: speech act theory, interactional sociolinguistics, conversation analysis, variation analysis, pragmatics, and ethnography of communication (Schiffrin, 1994), have been suggested up to now. These models draw on the premises of several disciplines of linguistics, anthropology, sociology, and social psychology to offer appropriate and systematic tools for observing, analyzing, understanding and critiquing classroom aims, events and communication. Although each approach emphasizes different aspects of language use, they all view language as a social interaction which is shaped by social contexts.

This study deals with one of the notion of poststructuralist, namely power/dominance, in classroom discourse. In her study on "Power and Gender", Savignon, S $(2006$, p. 88) tries to explain this issue " For Michel Foucault, the French intellectual whose collected texts remain the primary reference for what we know as a postmodern critical perspective, the power that comes with social and political status is ubiquitous in everyday life and interpersonal relations. Power influences not only what we can say and do but how we can say and do them. It also influences the opportunities we have to do so. In sum, power is the single most important organizing concept in social and political history. In characterizing the multifaceted nature of power, Foucault does not mean that we are without choice. Each of us makes choices in our daily lives. These choices may be reflected in the way we dress, the food we eat, the gestures we make, and the words we speak or choose not to speak. Choice is the equivalent of what has been termed 'personal agency'. And personal agency can generate power from the bottom up as well as from the top down. Freely imposed through discipline, the ordinary routines of everyday life, power is exercised rather than possessed. Workers as well as supervisors can exercise power". Based on this discussion, we analyzed the differences in the discourse of males and females from perspectives of a conventional model: Grice Cooperative Principles; and a critical model: Critical Classroom Discourse Analysis. Although many scholars don't indicate any place for Gricean pragmatics in ELT, this communication theory of language use could arguably be of highly valuable tool for reflective teachers who do not deal with "language as a system or product per se, but rather with the interrelationship between language form, messages and users" (Oatey and Zegarac in Schmitt, 2002, p. 74). The first section deals with an overview of Grice's Cooperative Principles (1975) and its application to analyze the relationship between learners' gender and their adherence to or violation of maxims in classroom interaction.

Furthermore, this study aims to show how teachers could use their classroom as a site of research to improve their knowledge and skills. Taking into account the importance of classroom research which urges the teachers to improve their teaching performance through research; "classroom discourse analysis" could be a viable tool that not only increases the learning opportunities (through monitoring input/interaction/output), but also it will help the teacher to theorize their own practice through self-reflection and reassessment of their situated knowledge.

\section{Analysis of Classroom Process}

Kumaravadivelu (1999) identified two widely used approaches to classroom observation, generally characterized as the Interaction approach and Discourse approach. Classroom Interaction Analysis involves the use of an observation scheme consisting of a finite set of preselected and predetermined categories for describing certain verbal behaviors of teachers and students as they interact in the classroom. The most renowned schemes was the Flanders Interaction Analysis Categories, proposed by Flanders in 1970 which resulted in a much better understanding of classroom aims and events, particularly in terms of teacher talk and student talk. Another observation scheme for Interaction analysis, Communicative Orientation of Language Teaching (COLT), was developed by Allen, Fröhlich, and Spada (1984). However, COLT remained basically Flandersian in the sense that the basis of observation was largely confined to observable, codifiable, and countable behavior of learners and teachers (Spada and Fröhlich, 1995).

However, Kumaravadivelu (1999, p. 456) criticized the interaction approach to classroom observation due to its "fragmented picture of classroom reality" which he believed led to the emergence of alternative analytical schemes that can be grouped under the rubric of classroom discourse analysis. Highlighting the need to contextualize the actions and contributions of participants in the classroom, van Lier "takes the educational environment (with the classroom at its centre) as the crucial data resource and thus strongly emphasizes the social context in which language development takes place" (p. 24). Meanwhile, The interpretive nature of classroom discourse analysis advocated by Allwright (1980) and van Lier (1988) also entails an analysis of multiple perspectives_the teacher's, the learner's, and 
the observer's (researcher's)_on classroom discourse (ibid).

But, Classroom discourse analysis is subject to criticism too: the neglect of the broader sociocultural and sociopolitical dimensions of classroom discourse analysis due to its scope and method. Its scope has been confined mostly to treating the classroom as a self-contained minisociety insulated and isolated from the outside world. Likewise, the preferred method of classroom discourse analysts - microethnography - has enabled them to study crucial classroom issues such as input and interaction, form and function, but overlook broader social, cultural, political, and historical structures (Kumaravadivelu, 1999. P. 471).

\section{Gricean's Theory of Conversation}

"No man would listen to you talk, if he didn't know it was his turn next."Edgar Watson

To learn a language is to learn how to communicate in that language, which is a dynamic, interactive and irreversible act. In his remarkable paper "Logic and Conversation (1975)", Grice suggested that there are certain constraints that govern conversation and limit the interlocutors as to what they can say and infer. Grice called the overriding principles of conversation as "cooperative principles", which stipulates: "Make your conversational contribution such as is required, at the stage at which it occurs, by the accepted purpose or direction of the talk exchange in which you are engaged. He lists four maxims that follow from the cooperative principle: Quantity: make your contribution as informative as is required. Do not make your contribution more informative than is required (Don't be loquacious). Quality: Do not say what you believe to be false or for which you lack adequate evidence (Don't be phony). Relation: Be relevant (Don't be rambler). Manner: Avoid obscurity of expression; avoid ambiguity; be brief; be orderly "(Don't be opaque).

Adherence to the maxims is rational, though not prescribed, because it ensures that the interlocutors pursue the shared goal most efficiently. But talk would be extremely tedious if you just observe the maxims. Grice proposed that speakers may frequently fail to observe any of above conversational maxims that may lead to violation, opting out, infringing and flouting. Violation is a sort of breakdown in communication due to irrelevant, unclear or insufficient information to misinform or mislead your interlocutor (Quietly and unostentatiously, no implicature). Clashing is conflict between maxims; i.e. to avoid violating the maxim of quality, you violate the maxim of quantity. Flouting is when the speaker chose to blatantly and deliberately not observe a maxim. Through flouting speaker seeks to prompt the hearer to look for a meaning which is different from, or in addition to, the expressed meaning, called 'conversational implicature'.

The Cooperative Principles can be used as the cornerstone of investigating the 'ground-rules' of classroom discourse to gain an insight over social interaction. But, there are some criticisms which shed doubts on Grice theory, both theory-wise and practice-wise.

First of all, Grice classification is completely borrowed from a philosophical and pre-linguistics theory, ambitiously and directly transferred to the domain of discourse description, without any reformulation or adjustment. Do the maxims' definitions precisely specify their concrete nature or they are just some general, vague rules that lead to bafflement instead of enlightenment? For e.g. maxim of quantity stipulates:"be as informative as required"; what determines the exact "degree of informativeness". Another problem, as sensibly alluded by Levinson (1983, p. 109) is overlap among maxims, e.g.it is not possible to determine whether irony is a flouting of quality or relevance maxim! Irony seems to flout both of them simultaneously, and maybe maxim of manner, too!

Furthermore, Gazdar (1979) \& Hirschberg (1985) pointed out that maxims can't be directly transplanted to empirical work, such as classroom discourse analysis and teacher research. There is apparently no consistent model of the how $\mathrm{CP}$ should be applied in describing across different discourse genres: e.g. Classroom discourse, courtroom discourse and friendly-talk each reveals certain features, quite peculiar to their own genres. According to Grice to determine what was said one has to disambiguate the sentence (i.e. to select one of its possible readings), and assign referents to all referential expressions. Grice claimed that this is everything one has to do. Nowadays many authors assume that the gap between the meaning of the sentence and what is said is wider than Grice suggested. In many cases the under-determination is not limited to reference-assignment and disambiguation. Hence many authors have tried to find new criteria to distinguish between what was said and what was implicated.

\section{Critical Classroom Discourse Analysis (CCDA)}

Dissatisfied with previous models of classroom interaction analysis, Kumaravadivelu (1999, p: 466-470) criticized classroom interaction analysis in terms of their definition, scope and method. In terms of discourse definition, he believed "if discourse can be seen as a three-dimensional construct consisting of a (socio) linguistic dimension, a sociocultural dimension, and a sociopolitical dimension, then previous classroom discourse analysts may be considered to be involved with the first, interested in the second, and indifferent to the third". Critical Classroom 
Discourse Analysis (CCDA), on the other hand, assumes that classroom reality is socially constructed, politically motivated, and historically determined. It is mainly concerned with Foucault's view (1972) of discourse that "empowers and disempowers privileges and marginalizes". As practitioners, we have to encourage our learners to "deconstruct dominant discourses as well as counter-discourses by posing questions at the boundaries of ideology, power, knowledge, class, race, and gender" (Kumaravadivelu, 1999. P. 476). The poststructural and postcolonial discourse perspectives lay the ground for formulating the nature, scope, and method of CCDA.

The following principles of CCDA is are used in this study:

- Classroom discourse, like all other discourses, is socially constructed, politically motivated, and historically determined;

- The L2 classroom is not a secluded, self-contained minisociety; it is rather a constituent of the larger society in which many forms of domination and inequality are produced and reproduced for the benefit of vested interests;

- The L2 classroom also manifests, at surface and deep levels, many forms of resistance, articulated or unarticulated;

- The negotiation of discourse's meaning and its analysis should not be confined to the acquisitional aspects of input and interaction,

- Teachers need to develop the necessary knowledge and skills to observe, analyze, and evaluate their own classroom discourse.

The major methods of data collection in CCDA are: gathering of spoken and written, audio and video data from multiple sources, including interactional episodes, participant observation, and interviews and discussions with participants at different times and levels, or in Greetz's term (1973) thick description and thick explanation.

\subsection{Objectives}

Van Lier (1988) rightly argues that classroom research must "expose complex relationships between individual participants, the classroom, and the societal forces that influence it" (p. 82). Meanwhile, they asked for multiple perspectives of participants; e.g. the researchers, the teachers and the learners in collection and interpretation of data. In this study, we considered the classroom as an integral part of the larger society where the representation of power and domination, based on gender factor, could be observed and analyzed.

To examine the relationship between genders and power/dominance, we exploited two models of classroom interaction analysis: a) Grice Maxims which gives a descriptive analysis and a micro-perspective of the conversation, and b) a macro-perspective framework: Critical Classroom Discourse Analysis. In stark contrast to the claims that Gricean pragmatics as intrinsically interesting, but of little practical adaptability to the language teaching context, we aime to apply the Grice theory to analyze the relationship between learners' gender and their adherence to or violation of maxims in classroom interaction. Meanwhile, since the mere description might provide us just with a superficial and fragmented picture of the classroom talk, to unveil the underlying structures, motivations, agendas and voices, we used two approaches proposed by Grice (1975) and Kumaravadivelu (1999) as complementary.

\subsection{Research Questions}

This study mainly deals with the following research questions:

1. Do different genders (Males vs. Females) show different levels of "Power" in the classroom interaction?

3. Do different genders (Males vs. Females) use different strategies in exerting "Dominance" in the classroom interaction?

\section{Methodology}

"There is no such thing as 'objective' observation. What we see will be determined by what we expect to see." (Nunan 98)

To contextualize the actions and contributions of participants; and due to the complexity of subject matter, this study used an ethnographically interpretive approach toward analyzing classroom interaction.

Transcriptions of classroom interaction of 22 EFL learners (12 females, 10 males) studying at semester eight of University will be analyzed. Later, we discus that this approach is quite limited, since it was unidimensional (from observer's perspective) and only provided us with a fragmented picture of classroom reality without any clue about the hidden motivations of dealing with maxims. Description of this type, then, sees dominant discourse conventions as natural (instead of naturalized product of power relations) and perpetuates the unjust status quo that marginalizes less powerful groups.

Thus, we utilized another approach called Critical Classroom Discourse Analysis (CCDA) which is mainly 
concerned with critiquing existing educational institutions and practices, and subsequently transforming both education and society (Hall, 2000, p. 3; Benesch, 2001; Giroux, 1988; Pennycook, 2001). This model is more qualitative, interpretive and ethnographic than Grice's prescriptive, quantitative model with predetermined categories. This study revealed how this model contributed to learners in gaining critical awareness about their gender/identity and helped the teacher to reconceptualize her cognition as well as practice.

\subsection{Participants}

This study is conducted in an English Language classroom with 22 EFL learners, 12 females and 10 males. Learners' level of proficiency was mainly assessed as upper-intermediate and advanced based on an informal interview conducted at the beginning of the course by teacher. Most of the learners admitted that they had exposure to other sources at the time of the study; e.g. some worked as translators in companies, other were involved in teaching in institutions; or even providing movie subscription.

\subsection{Procedure}

The class was held once a week over four months (totally 18 sessions). Each session lasted 100 minutes. The course title was oral interpretation and the learners were supposed to gain an acceptable level of proficiency in simultaneous translation; both from $L_{1}$-to- $L_{2}$ and vice versa. There was no fixed syllabus (though the coverage of the course required us to use some mandatory materials); thus learners were asked to bring some materials which were utilized beside mandatory ones. Audio/video materials received more positive reaction due to its multi-media, dynamic nature. We have selected a host of topics which seemed to be related to the socio-cultural context and educational themes of the learners. A set five comprehension questions (mainly open-ended), designed to be applied in small groups, was given to the learners which gave a sense of authenticity encouraged the learners to engage in more discussion activity. We advised our learners to support a main idea (maxim of relation), to elaborate (maxim of quality) and to create well-formed utterance through clear and ordered conversation (maxim of manner). During their interaction; learners were told that their performance would be assessed on the basis of four principles: brevity, orderdness, clarity and relevance.

\subsection{Data Analysis}

Data were gathered from learners' performance on Oral Interpretation course. Sixteen sessions of classroom interaction were recorded. Later, data extracts were selectively and purposefully transcribed and examined in detail. Data were triangulated from three sources: in-depth observation by teacher in the classroom; audio-taping of classroom interaction and reflective analysis of field notes gathered by teacher. (See Table 1)

Through transcription of interaction; we counted the number of violations. The results just indicated that males violated the maxims quite more frequently than females. However, Griceans' Maxims alone could not be used as a sole resource to analyze interaction. For instance, language acts that run counter to Grice's Maxims are called "violations". What if, in a particular culture, violations are not at all violations; rather, they are norms instead of maxims. Does the explanatory power of theory evaporate and the theory itself turns out to be either a mere abstract conceptualization or a groundless prescription for language use?

An inductive, iterative analysis of data was conducted from the beginning. The contents of classroom observation were transcribed. Constant comparison of the similarities and contradictions of data, with respect to the research questions, led to the coding of early categorical themes. These emerging themes and codes were shared with other team members for evaluation: some were modified or adjusted for subsequent data collection and analysis. Further re-analysis of data led to five major qualitative themes which could be used as explanatory codes to reveal the differences between the interaction of males and females based on their struggle for power/dominance.

\subsection{Results \& Discussion}

There may be several suggestions to justify these results, such as cultural schemata, different social roles, gender issues, various linguistic repertoires and so on. But, it is not exactly clear what propelled different genders to violate maxims. Did they have the same motivations or reasons to violate or adhere to maxims at particular times or during particular discussions? What we need is a meaningful and true understanding of the sociocultural aspects of maxim observance/violation which can't be achieved just through the surface-level features of conversational exchange between genders; rather we have to appraise the competing and complex world of discourses that exist in the classroom. To get a clue over these issues, a qualitative analysis of interaction between male-female revealed the following qualitative themes in their classroom discourse. (See Table 2)

As you could see in the following examples, in most of the exchanges, we observed male learners tried to take the floor and didn't allow female learners to participate much. Thus male learners mostly broke Quantity Maxim for domination. On other hand, female learners often broke Maxim of Quantity for a totally different purpose: to avoid 
imposing; or to be more polite, sympathic, and modest.

Theme A: Status vs. Support

_Topic: their opinion regarding taking mid-term exam

Male participant: No, I don't believe that we need to cover the whole material for mid-term exam. We could skip some.

Female participant: Well, if others want to skip some chapters, it's Ok with me.

Theme B: Independence vs. Intimacy

_ Topic: on their response to a newly-assigned group work.

Male participant: Well, it's a bit complicated. Let me check it first.

Female participant: I guess I need to consult my group-mate. I can't figure it out myself.

Theme C: Advice vs. Understanding

_Topic: on their discussion about "Literacy"

Male participant: why they are poor? Cause they "Have to" be more educated, which brings them more job opportunities.

Female participants: you know, they "might" not have the same and equal facilities. That's why some people are poor and illiterate.

Theme D: Information vs. Feelings

_Topic: on their discussion about "World-war II"

Male participant: As far as I gathered, the war was launched by these countries.... in....which led to the killing of ......milions people.

Female participant: I understood that war could have some awful consequences for family. It can turn a human into a beast; even a child can kill her mother.

Theme E: Orders vs. Proposals

_Topic: handing in their assignments

Male participant: we want more time, it takes time. Yes, we "want" at least two weeks

Female participant: can't we spend less time on listening and instead do some parts in group?

Theme F: Conflict vs. Compromise

_Topic: their opinion about Literacy

Male participant: ... Who says that! I'm sure this won't solve any problem. The researchers could advise as much as they want; but they are not practical

Female participant: I assume this idea could be fulfilled in the case the government and individuals trust each other.

Sometimes, females violated the quality maxim of cooperative principle, mostly in the context of responding to compliments, the Modesty Maxim clearly outweighs quality maxim, e.g. sarcastic remark addressed to a male student to express dissatisfaction and annoyance at his poor performance, and still this over flatter gentleman to exert power.

Males, being socially more powerful, are able to define the conditions that prevail in a given social situation, including the right to flout a conversational maxim. Flouting of Grice maxims included not providing all information required, using derogative terms, being deliberately vague, providing conflicting stories, giving unnecessary background information, and offering confused and/or misleading accounts. They deliberately exploit the maxims for deriding and showing their dissatisfaction without directly going into the danger of confrontation. They tended to be more competitive, lecturer, take the floor, exclusive. When they were in power, they tend to use more male strategies, being less indirect, fewer politeness, and more negative face. But after several sessions; the females, under certain adverse circumstances, begun to manipulate and subvert the males' argument.

About four sessions were devoted to gender issues; during which we examined the sociocultural conditions and inequalities that different genders may encounter in their own society. We admit that it might take more time to deal with this issue, but we hope that students become aware that most of the expectation and limitations for females and males are socially constructed, which shouldn't be treated as status-quo. 


\section{Conclusion}

The transformative thrust of CCDA, with its potential to create and sustain critical sensibilities, has serious implications not only for the ways TESOL professionals observe, analyze, and interpret classroom aims and events but for curricular objectives and instructional strategies as well (Kummaravadivelu, 1999. P. 479). We tried to incorporate a framework called Critical Classroom Discourse Analysis which is mainly informed by poststructural and postcolonial thoughts on discourse; springing a critical look at the discourses and counter-discourses that shape and reshape practices in ESOL classrooms (Kumaravadivelu, 1999, p. 479).

Classroom interaction of an oral interpretation course; with 22 EFL learners (12 females, 10 males) studying at semester eight of Translation major; was critically analyzed through Grice and Kumaravadivelu framework. The former framework is more quantitative and descriptive; while the latter is more qualitative and interpretive. The ratio of maxim violation by two genders was analyzed through Grice principles and the interpretation of the results to reveal the hidden motivations behind maxim violation was examined through CCDA. Qualitative data analysis indicated that males tended to be lecturers; used more negative face; more exclusive; competitive; took and held the floor more. On the other hand, Females were listeners; used more positive face; more inclusive; social, and tended to share the floor.

Although 22 learners and 16-week semester could not be considered a perfect reliable sample from which the results can be generalized; the main goal of this study is to raise awareness about how power and dominance might be presented and reproduced through the agencies of different genders in their classroom interaction and their everyday discourse. Thus, interactional styles which are exhibited in EFL situation could be ascribed to cultural disposition and ideologies which may reflect structures of the wider society.

\section{References}

Allwright, R. L. (1980). Turns, topics and tasks: Patterns of participation in language learning and teaching. In D. E. Larsen-Freeman (Ed.), Discourse analysis in second language research.

Benesch, S. (2001). Critical English for Academic Purposes: Theory, Politics and Practice. New Jersey: Lawrence Erlbaum Associates Inc.

Biddle, B. J. (1967). Methods and Concepts in Classroom Research. Review of Educational Research, 37, 337-357

Brown, P., \& Levinson, S. C. (1987). Politeness: Some universals in language usage. Cambridge: Cambridge University Press.

Foucault, M. (1972). The archaeology of knowledge and the discourse on language (A. M. Sheridan Smith, Trans.). New York: Pantheon Books.

Gazdar, G. (1980). Reply to Kiefer. Linguistic Investigations, 3, 375-377. http://dx.doi.org/10.1075/li.3.2.11gaz

Giroux, H. A. (1988). Schooling and the struggle for public life: critical pedagogy in the modern age. Minneapolis: University of Minnesota Press.

Geertz, C. (1973). The interpretation of cultures. New York: Basic Books.

Grice, H. P. (1975). Logic and conversation. In P. Cole, \& J. Morgan (Eds.), Syntax and semantics 3: Speech acts. New York: Academic Press. pp. 41-58

Grice, H. P. (1989). Studies in the way of words. Cambridge, MA: Harvard University Press.

Goffman, E. (1967). Interaction Ritual. New York: Doubleday Anchor.

Ivanic, R. (1998). Writing and identity: the discoursal construction of identity in academic writing. John Benjamins Publishing Company.

Kleifgen, J. A. (1990). Pre-kindergarten children's second discourse learning. Discourse Processes, 13, 225-242. http://dx.doi.org/10.1080/01638539009544755

Kumaravadivelu, B. (1999). Critical classroom discourse analysis. TESOL Quarterly, 33(3), 453-484. http://dx.doi.org/10.2307/3587674

Levinson, S. C. (1983). Pragmatics. Cambridge: Cambridge University Press. pp. 109

Lakoff, Robin T. (1995). "Conversational logic”. Handbook of Pragmatics, Verschueren, Jef, Jan-Ola Östman. Jan Blommaert and Chris Bulcaen. pp. 190-198

McClellan, J. (1971). Classroom-Teaching Research: A Philosophical Critique. In Westbury, I., \& Bellack, A. (Eds), Research into Classroom Process. New York Teachers' College, Columbia University.

Nicolas, A. (1986). Interaction Analysis. American Educational Research Journal, 5, 285 
Norton, B. (2000). Identity and language learning: Gender, ethnicity and educational change. Harlow, England: Longman/Pearson Education.

Spencer-Oatey, H., \& V. Žegarac. (2002). Pragmatics. In N. Schmitt (Ed.), An introduction to applied linguistics. London: Arnold. pp. 74-91

Pennycook, A. (2001). Critical Applied Linguistics: A Critical Introduction. Mahwah, New Jersey \& London, Lawrence Erlbaum Associates.

Peirce, N. B. (1995). Social identity, investment, and language learning. TESOL Quarterly, 29(1), 9-31

Savignon, S. J (2006) Gender and power in applied linguistics: an epistemological challenge. International Journal of Applied Linguistics, Vol. 16w, No. 1

Saddock, J. M. (1978). On Testing for Conversational Implicature. In: P. Cole (ed.), Syntax and Semantics 9: Pragmatics. New York. pp. 291-298

Schiffrin, D. (1994). Approaches to Discourse. Oxford: Blackwell. pp. 190-203

Sperber, D., \& D. Wilson. (1989). On Verbal Irony. UCL Working Papers in Linguistics, 1, 96-118

Strawson P. F. (1950). On Referring. Mind, 59(235), 320-344. http://dx.doi.org/10.1093/mind/LIX.235.320

Tannen, D. (1986). That's not what I meant: How conversational style makes or breaks your relations with others. Morrow, New York.

Van Lier, L. (1988). The Classroom and the Language Learner. Ethnography and Second-Language Classroom Research. Harlow: Longman.

Young, R. (1992). Critical theory and classroom talk. Clevedon, England: Multilingual Matters.

Wierzbicka, A. (1992). Semantics, Culture and Cognition: Universal human concepts in culture-specific configurations. New York: Oxford University Press.

Table 1. Data analysis

\begin{tabular}{|l|c|c|c|c|}
\hline violation & Quantity & Quality & Manner & Relation \\
\hline Female & 14 & 8 & 3 & 12 \\
\hline Male & 22 & 12 & 25 & 20 \\
\hline
\end{tabular}

Table 2. Qualitative themes

\begin{tabular}{|c|c|c|c|c|c|c|}
\hline Qualitative Themes & A & B & C & E & F & G \\
\hline Female & Support & Intimacy & Understanding & Feelings & Compromise & Proposals \\
\hline Male & Status & Independence & Advice & Information & Conflict & Orders \\
\hline
\end{tabular}

